\title{
Effects of Different Seeds Pretreatments on the Germination of Five Local Trees: Four From The Fabaceae Family and One From the Bombacacea
}

\section{Yélemou Barthelemy,}

Institut de l'Environnement et de Recherches Agricoles (INERA)/Centre

National de la Recherche Scientifique et Technologique (CNRST), BP 10

Koudougou, Burkina Faso

Tyano Abdoulaye,

Institut de l'Environnement et de Recherches Agricoles (INERA)/Centre National de la Recherche Scientifique et Technologique (CNRST), BP 10

Koudougou, Burkina Faso,

Université Nazi Boni, Laboratoire des systèmes Naturelles, des Agrosystèmes et de l’Ingénierie de l’Environnement (Sy.N.A.I.E)

\section{Koala Jonas,}

Institut de l'Environnement et de Recherches Agricoles (INERA)/Centre

National de la Recherche Scientifique et Technologique (CNRST), BP 10

Koudougou, Burkina Faso

\section{Zongo Rebecca,}

Ecole Nationale des Eaux et Forêts, Bobo Dioulasso

Doi:10.19044/esj.2021.v17n43p89

Submitted: 29 September 2021

Accepted: 12 November 2021

Published: 31 December 2021
Copyright 2021 Author(s)

Under Creative Commons BY-NC-ND 4.0 OPEN ACCESS

Cite As:

Barthelemy Y., Abdoulaye T., Jonas .K.,\& Rebecca Z.,(2021). Effects of Different Seeds Pretreatments on the Germination of Five Local Trees: Four From The Fabaceae Family and One From the Bombacacea European Scientific Journal, ESJ, 17(43), 89.

https://doi.org/10.19044/esj.2021.v17n43p89

\section{Abstract}

The problem of the effectiveness of the established pre-treatments of seeds of local tree species is posed more and more often, with acuity. It appears necessary that studies are led to explore new methods of pre-treatment, or to update the old instructions applied, for a better success and at lower cost, of the production of seedlings. The present study concerned five species: Acacia nilotica, Adansonia digitata, Parkia biglobosa, Piliostigma reticulatum and Tamarindus indica. The methodology involved subjecting the seeds to three 
different pretreatments: (i) seeds treated with sulfuric acid (T0), (ii) seeds soaked in hot water for 24 hours (T1), (iii) seeds soaked in hot water for 48 hours (T2). For Acacia nilotica seeds, the different pretreatments did not result in statistically different germination rates. The germination rates are $77 \%$, $65 \%$ and $62 \%$ (respectively for soaking in hot water for 48 hours, sulfuric acid and soaking in hot water for 24 hours). The different pretreatments also do not result in different germination rates for Tamarindus indica. Indeed, the germination rates after 30 days for this species are good but statistically identical (85\% for the pretreatment with sulfuric acid and hot water for 24 hours). For Adansonia digitata, Parkia biglobosa and Piliostigma reticulatum, the sulfuric acid pretreatment gave the best germination rate (49\%, 54\% and $41 \%$ respectively). The results of this study may have practical consequences in terms of management of the different species studied. They show that immersing in boiling water and left for 24 hours and 48 hours yields fairly satisfactory germination rates for Acacia nilotica and Tamarindus indica seeds. These inexpensive techniques, accessible to all, can be considered as means to easily produce seedlings of these species.

Keywords: Germination, Seeds, Dormancy, Pretreatment, Mimosoideae Species, Caesalpinioideae Species

\section{Introduction}

Burkina Faso is a Sahelian country located in the heart of West Africa and covers an area of $274,000 \mathrm{~km}^{2}$. Like other West African countries, the country has been experiencing a continuous degradation of natural ecosystems for several decades. Indeed, from 1980 to 1992, the area of forest formations regressed by 1.26 million hectares, from 15.42 million hectares in 1980 to 14.16 million hectares in 1992. From 1992 to 2002, total forest formations declined by an average of 107,626 hectares per year, or an average of $0.83 \%$ per year. Despite their approximate nature, these data reflect very well the extent of the general regression of forest areas. Nowadays, the state of forest degradation in Burkina Faso has been greatly amplified by the development of agricultural and livestock activities (Nikiéma et al., 2001). The main causes of this degradation are more anthropogenic than natural and the consequences are the erosion of habitats and biodiversity, the accentuation of food insecurity, etc. However, forest formations have always provided rural populations with various goods and services as well as substantial monetary income (Tyano et al., 2020). Faced with the magnitude of the challenge and in order to protect woody forest resources, the Ministry in charge of the environment and sustainable development has developed several techniques/technologies and strategies for the rehabilitation of degraded ecosystems, with a view to satisfying the needs of the populations (Garba et 
al., 2020). These techniques or technologies aim to restore degraded lands, reconstitute the vegetation cover, but also to improve the living conditions of populations by ensuring food security (Garba et al., 2020). However, the objectives targeted through these programs have not always been achieved, due to the absence of scientific planting programs of many native forest species of socio-economic importance, for several reasons including: the low availability of seeds due to conservation problems, seed purity, seed dormancy (Abdourhamane et al., 2014; Garba et al., 2020). There are also plantations of exotic species at the expense of local species due to the lack of control of reproduction and silviculture techniques (Thiombiano, 2005). It is therefore urgent to promote the planting of local species. This requires a mastery of reproduction and silviculture techniques, including the pre-treatment of seeds in order to lift the dormancy. Thus, this study has been initiated. The objective is to contribute to the improvement of breeding (or cultivation) techniques of local tree species.

\section{Methodology \\ Study site}

The study was carried out in the Institute of Environment and Agricultural Research (INERA) in Saria, Burkina Faso. The village of Saria is located in the province of Bulkièmdé, $23 \mathrm{~km}$ East of the city of Koudougou and $80 \mathrm{~km}$ Northwest of Ouagadougou, the capital (Figure 1). It lies between $12^{\circ} 16^{\prime}$ North latitude and $2^{\circ} 09^{\prime}$ West longitude at an altitude of $300 \mathrm{~m}$. The average annual rainfall recorded over the last ten years (2010 - 2020) was $885.19 \pm 112.23 \mathrm{~mm}$. The soils of Saria are of tropical ferruginous type, with upper horizons of silty-sandy to sandy-clayey texture. The vegetation cover is that of the North-Sudanian phytogeographic zone (Fontès and Guinko, 1995). The annual grassy savannas are characteristic of this zone. The population density of the Bulkièmdé province is $102 \mathrm{hts} / \mathrm{km}^{2}$, so there is a strong pressure on the land. 


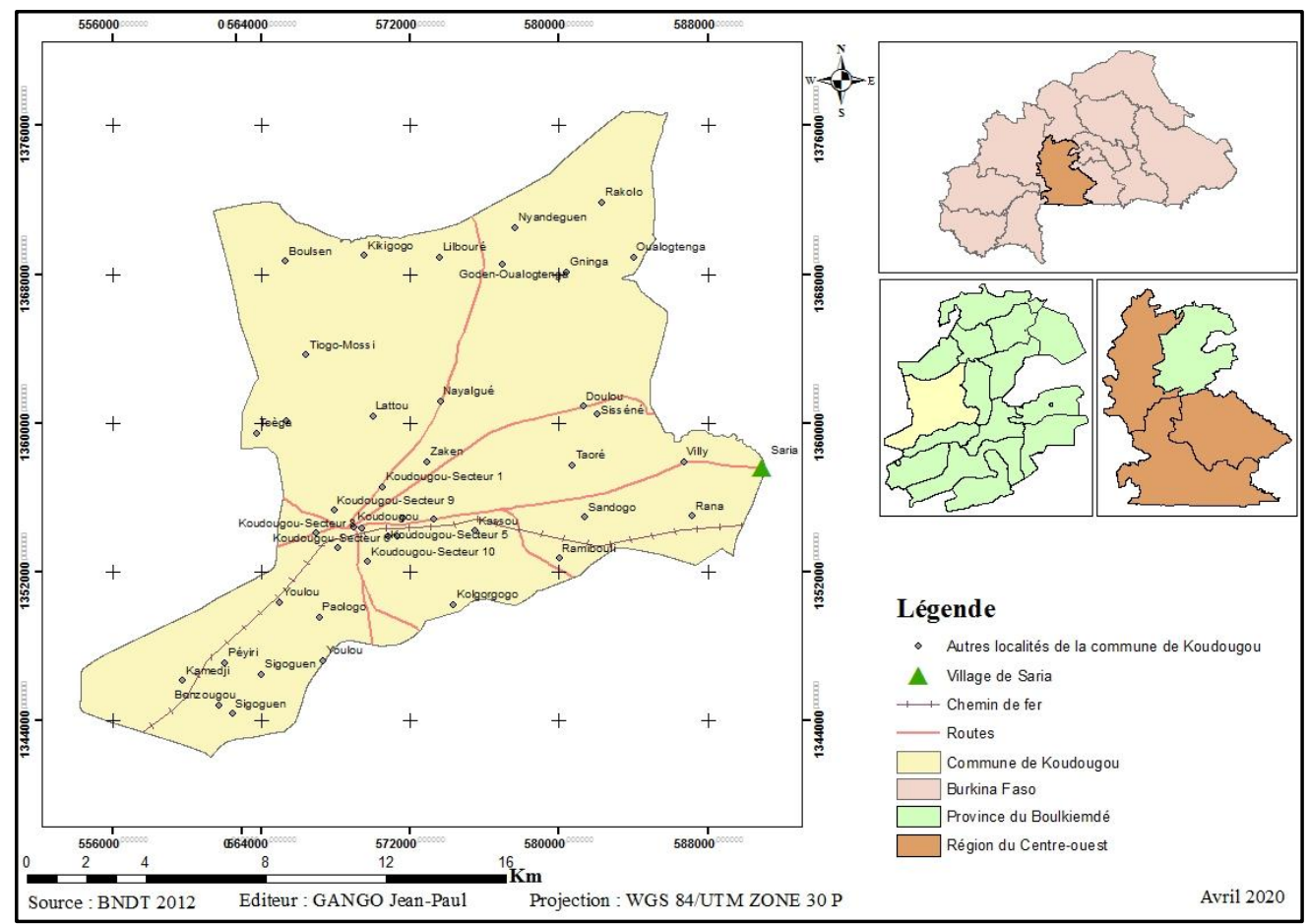

Figure 1: Location of the Study Area

\section{Methodology}

Study Species: Species concerned with this study are Acacia nilotica (L.) Willd. ex Del. (Mimosoideae), Adansonia digitata L (Bombacaceae), Parkia biglobosa (Jacq.) R. Br. ex G. Don (Mimosoideae), Piliostigma reticulatum (DC.) Hochst. (Caesalpinioideae) and Tamarindus indica L. (Caesalpinioideae) (Figure 2). The species chosen are the most frequent species in the savannas of the study area. Also, they are used on a daily basis by the populations for food and local medicines (Tyano et al., 2020). 


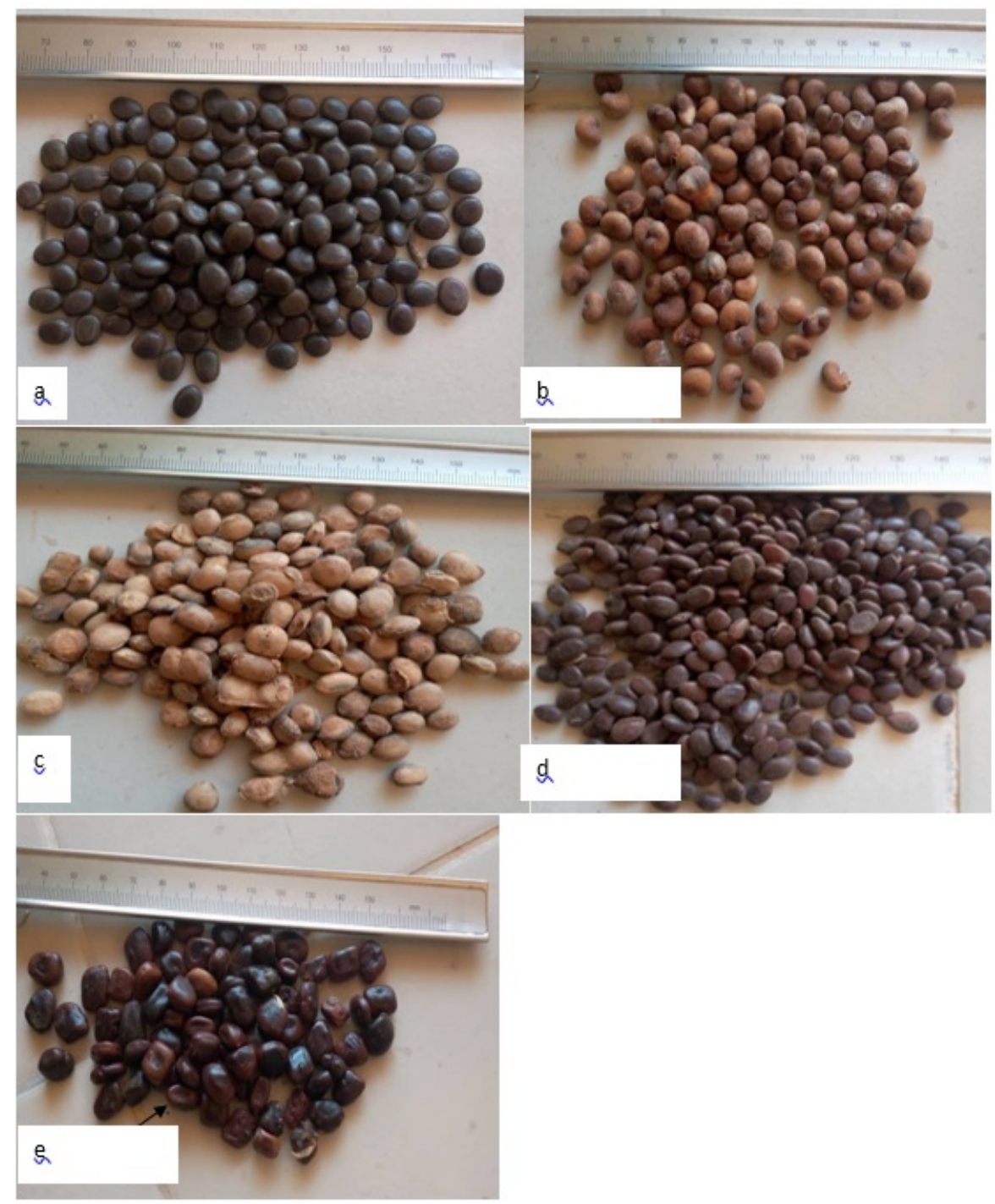

Figure 2: Illustrative images of seeds from studied species a: Acacia nilotica, b: Adansonia digitata, c: Parkia biglobosa, d: Piliostigma reticulatum, e: Tamarindus indica

Pre-germination treatments: Three types of pretreatments for dormancy breaking were applied to the seeds:

- $\mathrm{T}_{0}$ : Soaking in sulfuric acid for 15 minutes followed by rinsing with distilled water;

- $\quad T_{1}$ : Soaking in boiling water and left for 24 hours followed by rinsing with distilled water;

- $\quad \mathrm{T}_{2}$ : Soaking in boiling water and left for 48 hours followed by rinsing with distilled water. 
For the treatments with boiling water, the boiling water was poured on the seeds contained in a jar. The whole was kept at room temperature for 24 hours for T1 and 48 hours for T2.

Seedlings: After the application of the pre-germination treatments, the tree seeds were put in petri dishes and then placed on a germination table (Figure $3)$. The support in the petri dishes was blotting paper. The experimental design was made up of four (04) blocks or repetitions. Each repetition was composed of twenty-five (25) seeds, or a total of one hundred (100) seeds per species. The seeds were watered twice a day (morning and evening). The temperature of the experimentation is the room temperature: $37^{\circ} \mathrm{C}$. The blotting paper is kept regularly moist by watering every morning and evening.

Data collection: Data collection consisted of counting germinated seeds by species and by replicate for each pre-germinative treatment. The germinated seeds were put in new Petri dishes to avoid double counting. The counting was done every day at 8 am.

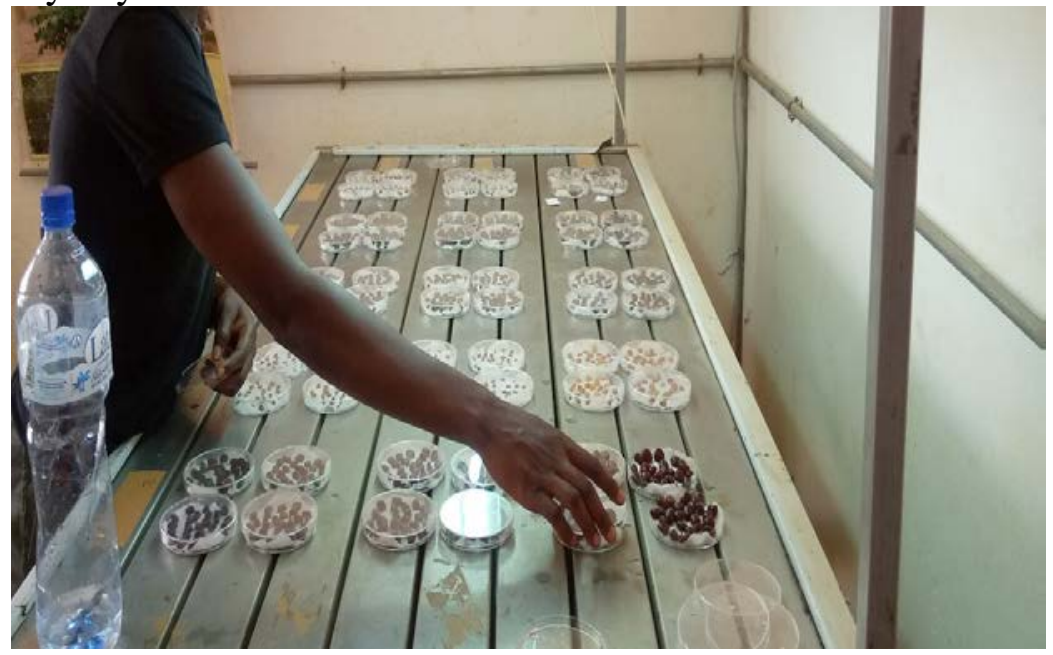

Figure 3: Illustration of the germination test device

Data analysis: The germination rate $(\mathrm{Gr})$ was calculated by the following formula (Bamba et al., 2018):

$$
\operatorname{Gr}(\%)=\frac{n}{N} X 100
$$

With $\mathrm{Gr}=$ germination rate, $\mathrm{n}=$ number of germinated seeds per replication and $\mathrm{N}=$ total number of seeds sown per repetition.

The collected data were entered into an Excel spreadsheet. The same spreadsheet was used to construct the graphs. An analysis of variance (ANOVA) was performed using the XLSTAT 2016.02.27444 statistical software. The Fisher test was used to compare the means at the 5\% probability level. 


\section{Results}

\section{Effects of different seed pretreatments on the germination of Acacia nilotica}

There were significant differences in germination rates of Acacia nilotica seeds during the first 15 days (Figure 4). Pre-treatment with sulfuric acid and hot water for 48 hours resulted in statistically different germination rates from those obtained by pre-treatment with hot water for 24 hours. Indeed, 5 days after the start/the onset the pretreatments with hot water during 48 hours and sulfuric acid allow a germination rate of both $6 \%$ whereas the seeds soaked in hot water during 24h did not present any germination. From the 20th day after sowing, all pre-treatments have similar germination rates. The germination rates obtained at the end of the trial were $77 \%, 65 \%$ and $62 \%$ (respectively for the pretreatments with hot water for 48 hours, sulfuric acid and hot water for 24 hours).

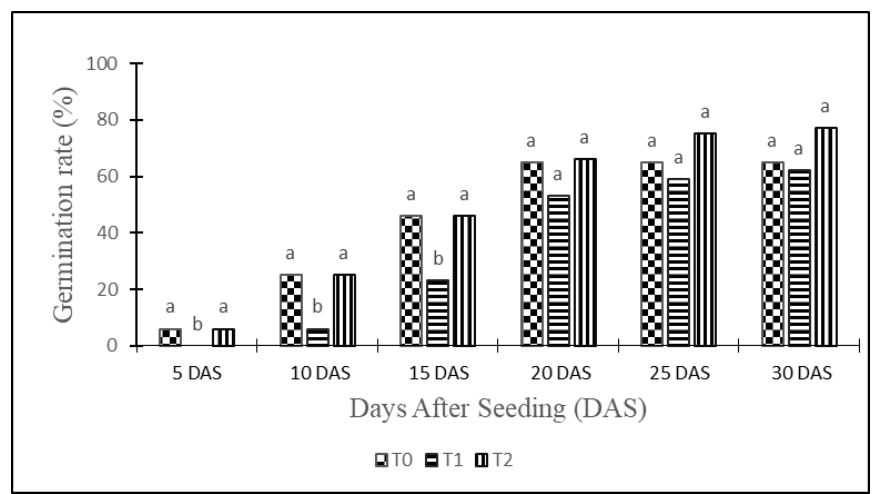

Figure 4: Evolution of the germination rate of Acacia nilotica seeds

The values expressed are the average germination rates. At the same date, the sticks, surmounted by the same letter are not significantly different a $\mathrm{p}<0.05$ according to Fischer test.

Effects of different seed pretreatments on the germination of Adansonia digitata.

There are significant differences between germination rates of Adansonia digitata L. seeds. The sulfuric acid pretreatment resulted in higher germination rates regardless of the number of days after sowing (Figure 5). Indeed, this pretreatment records a germination rate $(\mathrm{T} 0=15 \%)$ as early as the $5^{\text {th }}$ day after start (DAS) while the water pretreatments have germination rates of $10 \%$ and $4 \%$ respectively for the hot water pretreatment during 24 hours and during 48 hours. The germination rate at the 30th day after the start reached $49 \%$ for the sulfuric acid pretreatment (T0) while at the same date, it was $28 \%$ and $15 \%$ respectively for the hot water soaking for 24 hours (T1) and 48 hours (T2). 


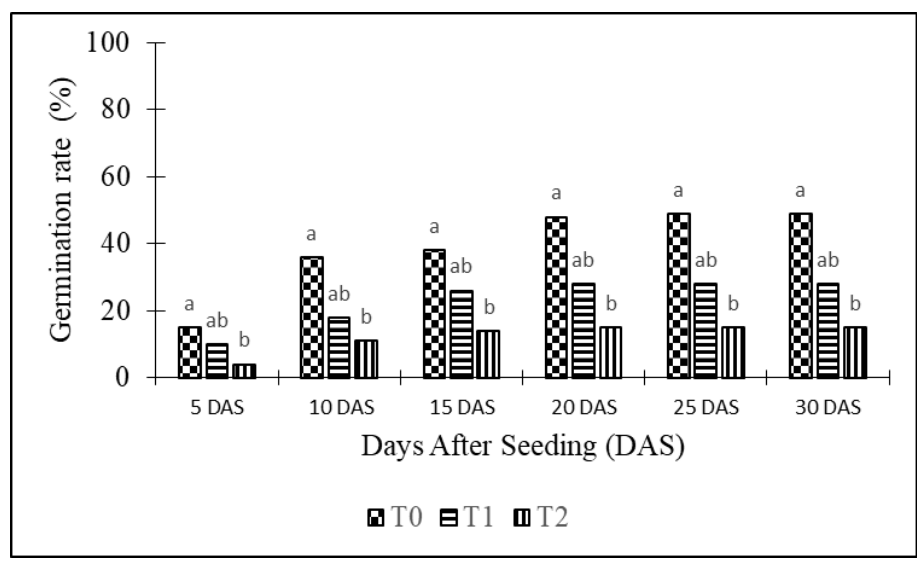

Figure 5: Evolution of the germination rate of Adansonia digitata seeds

The values expressed are the average germination rates. At the same date, the sticks, surmounted by the same letter are not significantly different a $\mathrm{p}<0.05$ according to Fischer test.

\section{biglobosa}

Effects of different seed pretreatments on the germination of Parkia

There were significant differences in germination rates of Parkia biglobosa seeds (Figure 6). Indeed, the sulfuric acid treatment had a germination rate of $28 \%$ at day 5 after the start while the other treatments (T1 and T2) had no germinated seeds. From the 10th day to the 30th day, the treatment with sulfuric acid remains the best treatment with a germination rate of 54\% whereas the treatment with hot water during 24 hours had a germination rate of $29 \%$ and the treatment with hot water during 48 hours had a germination rate of $17 \%$.

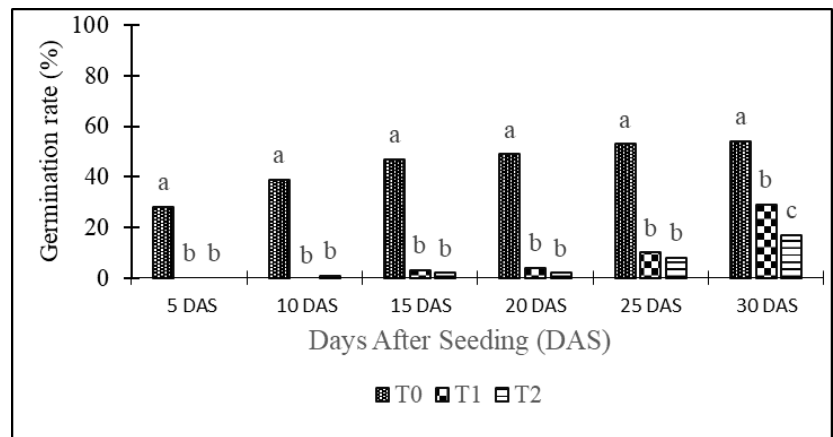

Figure 6: Evolution of the germination of Parkia biglobosa seeds

The values expressed are the average germination rates. At the same date, the sticks, surmounted by the same letter are not significantly different at $\mathrm{p}<0.05$ according to Fischer test. 
Effects of different seed pretreatments on the germination of Piliostigma reticulatum

There are significant differences between the germination rates of Piliostigma reticulatum. seeds. From the beginning to the end of the experimentation the treatment with hot water for 48 hours shows no germination (Figure 7). The sulfuric acid pre-treatment gave the best germination rate, whatever the observation date (23, 39 and $41 \%$ respectively at 10, 15 and 20 days). Pretreatment with hot water for 24 hours gives a low germination rate ( $4 \%$ from 15 days after sowing to the end of the experiment).

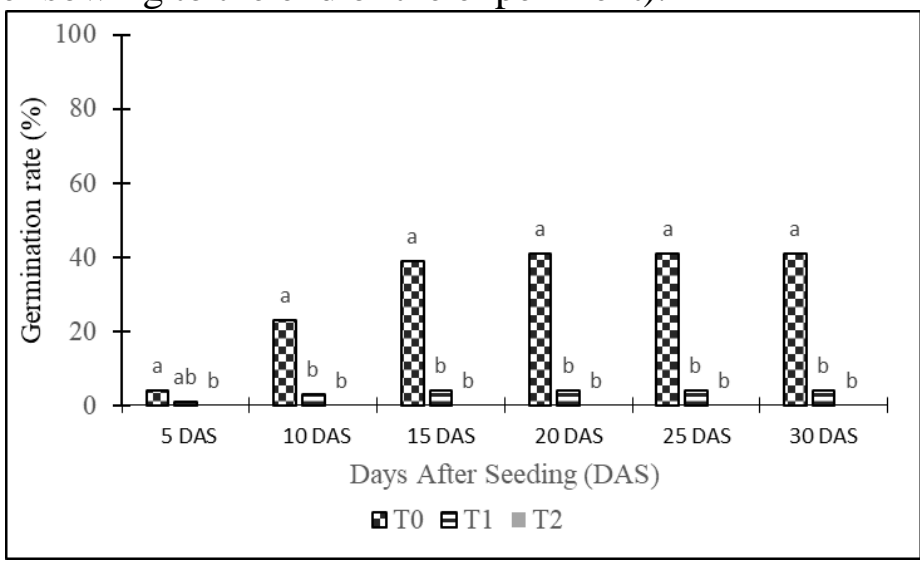

Figure 7: Evolution of the germination rate of Piliostigma reticulatum seeds

The values expressed are the average germination rates. At the same date, the sticks, surmounted by the same letter are not significantly different at $\mathrm{p}<0.05$ according to Fischer test.

Effects of different seed pretreatments on the germination of Tamarindus indica

There are significant differences between the germination rates of Tamarindus indica. Indeed, the germination of seeds treated with sulfuric acid is very fast compared to the other treatments (Figure 8). From the 10th day the germination rate of the seeds treated with sulfuric acid reached $83 \%$ while the seeds soaked in hot water for 24 and 48 hours had germination rates of only $28 \%$ and $14 \%$ respectively. Seeds soaked in boiled water started to germinate well from the 15th day. After 25 days, there were no significant differences between the germination rates of the different pretreatments. At the end of the experiment (30th day) the germination rates were $85 \%$ for the sulfuric acid and hot water pretreatment for 24 hours and $80 \%$ for the hot water pretreatment for 48 hours. 


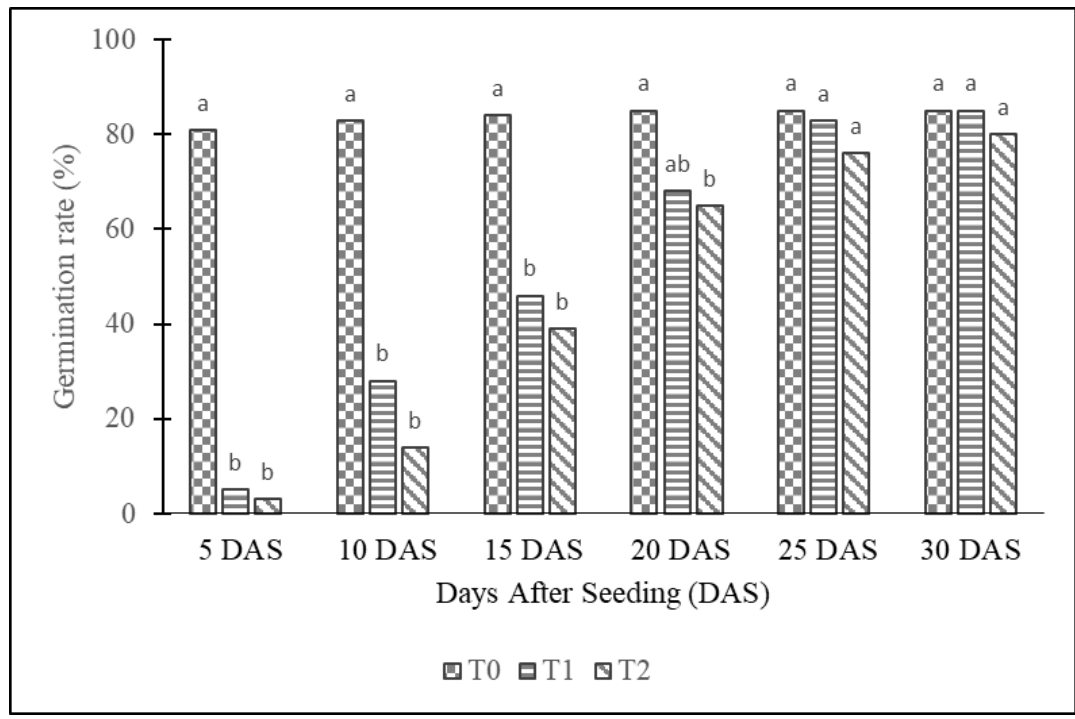

Figure 8: Evolution of the germination rate of Tamarindus indica seeds

The values expressed are the average germination rates. At the same date, the sticks, surmounted by the same letter are not significantly different a $\mathrm{p}<0.05$ according to Fischer test.

\section{Discussion}

The seeds of dryland leguminous trees are generally hard. This hardness is related to the presence of water-impermeability in teguments (Werker, 1981). Thus, these seeds have a dormancy that allows for long-term conservation of seeds, but requires lifting before sowing or else poor germination rates will result (Cavanagh, 1987). Pre-treatment of seeds prior to sowing results in rapid imbibition of the seed coat, and the entry of water triggers metabolic reactions in the seed embryo and rapid emergence of the radicle (Ahoton et al., 2009). The present study demonstrated that pretreatments of seeds before sowing not only shorten the germination time, but also increase the germination rate. Also the type of effective pretreatment varies among species. For Acacia nilotica and Tamarindus indica seeds, hot water is an effective treatment for the lifting of dormancy because seeds of Acacia nilotica and Tamarindus indica treated with hot water give good germination rates. As for the batches of seeds of Adansonia digitata, Parkia biglobosa and Piliostigma reticulatum soaked in hot water for 24 and 48 hours, the germination rate is very low compared to the batches of seeds treated with sulfuric acid. Therefore, sulfuric acid remains the best pretreatment for these three species. Seeds of Piliostigma reticulatum soaked in hot water for 48 hours did not germinate, which shows that long stays in water could lead to the loss of germinative capacity of some seeds. Garba et al. (2020), during a germination test of Tamarindus indica seeds in a nursery in Niger, found germination rates of 42.5; 37.5 (respectively for the pre-treatments of seed 
scarification and hot water soaking). The germination rates obtained for the same species during the present study are 85 and $80 \%$ respectively for the pretreatments with hot water during 24 and 48 hours. Our germination rates are therefore higher than those obtained by Garba et al (2020). This can be explained by the nature of the substrate used in the germination tests. In the present study, blotting paper was used and the experiments were carried out in the laboratory on a germination table. The germination tests carried out by Garba et al. (2020) were performed in a nursery on a substrate composed of $2 / 3$ dirt and 1/3 organic matter. Ouattara et al. (2019), after a study on the effect of sulfuric acid pretreatment on germination of Acacia auriculiformis A. Cunn ex. Benth. report that the germination rate of seeds that have not received any pretreatment is $20 \%$ while it is $80 \%$ for seeds pretreated with sulfuric acid. For these authors, tegument dormancy most often concerns species adapted to an alternation of dry and rainy seasons, and notably several leguminous genera such as Acacia, Prosopis, Ceratonia, Robinia, Albizzia and Cassia. The action of acid on the germination rate would be due to the fact that it would cause a scarification of the seed coat thus reactivating the physiological parameters and biochemical activities necessary for seed germination (Doran et al., 1983; Hakim et al., 2017).

\section{Conclusions}

Natural regeneration of local species is an important issue in agroforestry ecosystems in Burkina Faso. Through this study, the application of hot water pretreatments on seeds allowed to obtain better germination rates for some species. Thus, hot water treatments for 24 and 48 hours resulted in satisfactory germination rates for seeds of Acacia nilotica and Tamarindus indica. For other species such as Adansonia digitata, Parkia biglobosa and Piliostigma reticulatum, sulfuric acid remains the best pretreatment. The low germination rates of the latter three species with 48 hours scalding treatment compared to a $24 \mathrm{~h}$ scalding treatment indicate that the long stay of seeds in hot water may lead to the loss of germination capacity of some seeds. These results will undoubtedly be vital information for nursery training structures as they are scientific assets that we hope will generate greater interest leading to multiple studies regarding the restoration of endangered forest species of socio-economic importance. In addition, they will allow nurserymen to produce seedlings of local species with hot water at a lower cost. This technique is less expensive and accessible to all and has no side effects on human health and the environment compared to sulfuric acid, which is a chemical product and is very expensive.

\section{Acknowledgements}


The authors thank the project "Synergistic use and protection of natural resources for rural livelihoods through systematic integration of crops, shrubs and livestock in the Sahel" (SustainSahel) for funding this study.Abdourhamane H, Dan Guimbo I, Morou B, Mahamane A. (2014). Potential germination and initial growth of Sclerocarya birrea (A. Rich.) Hochst., in Niger. Journal of Applied Biosciences 76: 6433- 6443.

\section{References:}

1. Ahoton L.E., Adjakpa J.B., M’po Ifonti M’po \& Akpo E.L. (2009). Effet des prétraitements des semences sur la germination de Prosopis africana (Guill., Perrot. et Rich.) Taub., (Césalpiniacées). Tropicultura, 27, 4, 233- 238.

2. Bamba N., Ouattara N. D., Konan D., Bakayogo A., Tra Bi F.H (2018). Effets de cinq prétraitements sur la germination du vène (Pterocarpus erinaceus Poir., Fabaceae) dans la Réserve du Haut Bandama (Côte d'Ivoire). European Scientific Journal Vol.14, Nº 30 : 438-45.

3. Cavanagh T. (1987). Germination of hard-seeded what (order Fabales). In: Germination of Australian native plant seeds. Melbourne, Sydney, Australia, Inkata Press, p. 58-70.

4. Doran, J. C., Boland, D. J., Turnbull J. W. \& Gunn, B. V. (1983). Guide des semences d'acacias des zones sèches. FAO, Rome, 127p.

5. Fontès, J. \& Guinko, S. (1995). Carte de la végétation et de l'occupation du sol du Burkina Faso. Note explicative. Ministère de la coopération française, projet Campus, Toulouse, 68p.

6. Garba A., Saley K., Boube M., \& Sina A.K.S. (2020). Effets des prétraitements sur la germination des graines de Tamarindus indica L. (Fabaceae-Caesalpinioideae) en pépinière : proposition pour une restauration de l'espèce au Sahel. Journal of Applied Biosciences 149: $15362-15378$ p.

7. Hakim A. \& Daldoum M. A. (2017). Effect of different pretreatment methods and materials on germination potential of Faidherbia albida seeds. Scholars Journal of Agriculture and Veterinary Sciences 4(3): 86-90.

8. Nikièma A., Ouédraogo S.J. \& Boussim I. J. (2001). Situation des Ressources Génétiques Forestière du Burkina Faso. Note Thématique sur les Ressources Génétiques Forestières. Département des forêts Document FGR/22F FAO. Rome. Italie.

9. Ouattara K., Kouassi B.A. T., Soro D., \& Soro D. (2019). Effet des Prétraitements sur la Dormance des Semences de Acacia auriculaeformis A. Cunn. ex. Benth. (Fabaceae). European Scientific Journal 18 : 206-214. 
10. Thiombiano A. (2005). Les Combrétacées du Burkina Faso : Taxonomie, écologie, dynamique et régénération des espèces. Thèse de doctorat d'Etat ès-Sciences Naturelles, Université de Ouagadougou, Burkina Faso, 296 p.

11. Tyano A., Yélemou B., \& Hien M. (2020). Management and Use of Wood Resources in Agroforestry Parks in the Northern Sudanian Zone of Burkina Faso. International Journal of Innovative Science and Research Technology. Volume 5, Issue 11, November - 2020. Pp 437445.

12. Werker E. (1981). Seed dormancy as explained by the anatomy of embryo envelopes. Israel Journal of Botany, 29 : 22-44. 